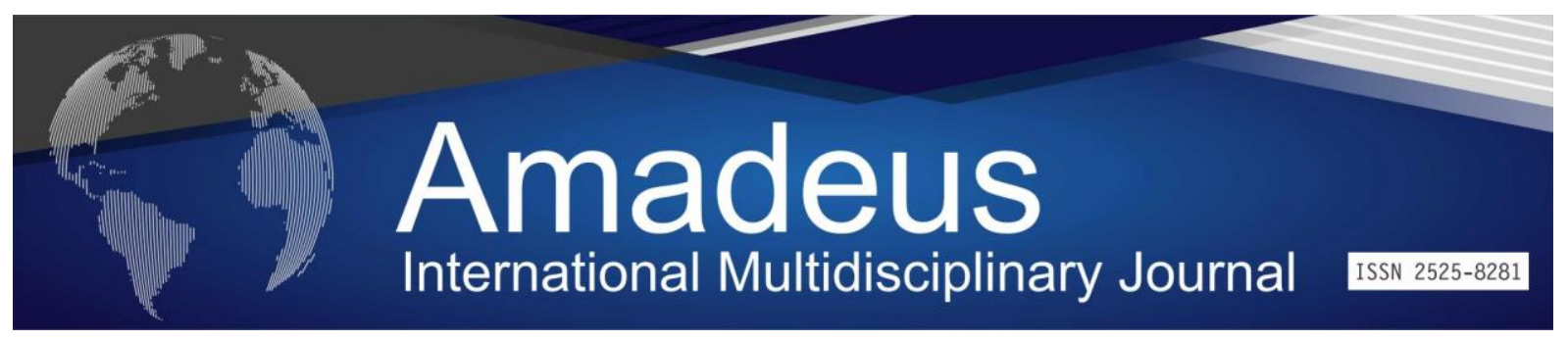

DOI: 10.14295/aimj.v4i7.74

\title{
The Law 9474/97 and the Protection of Refugee Minors
}

Paula Silvestre Campelo ${ }^{1}$; Maria das Graças Carvalho $^{2}$;

Patrícia Alencar ${ }^{3}$; Athena de Albuquerque

Farias $^{4}$

Eglidia Carla Figueiredo

Vidal

Carmem Ulisses Peixoto Esmeraldo ${ }^{6}$

\begin{abstract}
Currently, children account for almost half the number of refugees around the world, generally a fragile group, vulnerable to their own characteristics, especially when unaccompanied, which is not uncommon among refugee children. In this sense, special attention must be paid to the regulatory instruments that grant some protection and special observance to such individuals, so that the vulnerability framework is not strengthened. Brazil has some of the most developed legislation on the subject, as well as a broad organizational network and civil society entities responsible for assisting refugees and applicants throughout its territory. This study discussed law 9474/94 on the protection of refugee children in Brazil. It was concluded that adequate legislation is an essential prerequisite for a country to be able to provide and better serve refugee children, who are normally at risk and vulnerable.
\end{abstract}

Keywords: Refugee child; Vulnerability; Protection of minors.

\footnotetext{
${ }^{1}$ Graduação em Gestão de Recursos Humanos. Mestre em Ciências da Educação Pela Universidade Lusófona de Humanidades e Tecnologias de Lisboa. Pós-graduação em Gestão Estratégica de Pessoas pela Faculdade Leão Sampaio e Especialização em Docência do Ensino Superior pela Faculdade de Formação de Professores de Araripina-PE (FAFOPA). Graduanda em Direiro pela Faculdade Paraíso. paulascampelo@ hotmail.com;

2 Mestrado em Ciências da Educação pela Universidade Lusófona de Humanidades e Tecnologias - ULHTLisboa/Portugal. Graduação em História pela Faculdade de Formação de Professores de Araripina-PE - FAFOPA. Especialização em: Metodologia do Ensino Superior(AEDA); Psicopedagogia em Educação (Leão Sampaio) ; Historia e sociologia (URCA)Educação contextualizada no semiárido (UESPI); Politicas Educativas e Docência do Ensino Superior(AEDA). Grace.arthur@ hotmail.com;

${ }^{3}$ Graduada em Administração pelo Centro Universitário Doutor Leão Sampaio/UniLeão.

patriciaalencar133@gmail.com;

${ }^{4}$ Graduada em Direito pelo Centro Universitário dos Guararapes - UNIFG. Especialista em Direito Processual e do Trabalho pelas Faculdade Integrada de Cruzeiro, São Paulo, Brasil. Mestranda em Sustainable Development at the Università degli Studi di Milano. athena.farias@gmail.com;

${ }^{5}$ Graduação em Enfermagem pela Escola de Enfermagem Santa Emília de Rodat. Graduação em Bacharelado em Ciências Contábeis pela Universidade Federal da Paraíba. Mestrado em Enfermagem pela Universidade Federal do Ceará. Doutoranda em Enfermagem pela Universidade Federal do Ceará. Eglidia.vidal@urca.br;

${ }^{6}$ Graduada em Medicina pela Universidade Federal de Pernambuco (UFPE). Doutorado em Ciências da Saúde na Faculdade de Medicina do ABC-SP. Mestrado em Saúde da Criança e do Adolescente na Universidade Estadual do Ceará. Professora da Faculdade de Medicina da Universidade Federal do Cariri. carmem.peixoto@ufca.edu.br.
} 


\title{
A Lei 9474/97 e a Proteção a Menores Refugiados
}

\begin{abstract}
Resumo: Atualmente as crianças totalizam quase metade do quantitativo de refugiados ao redor do mundo, em geral um grupo frágil, vulnerável por suas próprias características, principalmente quando desacompanhadas, o que não é raro entre crianças refugiadas. Neste sentido, torna-se urgente uma atenção especial aos instrumentos regulatórios que conceda alguma proteção e observância especial a tais indivíduos, de forma a que não seja potencializado o quadro de vulnerabilidade. O Brasil possui umas das legislações mais desenvolvidas sobre o tema, além de deter uma ampla rede organizacional e entidades da sociedade civil, responsáveis por auxiliar os refugiados e os solicitantes em todo o seu território. Este estudo discutiu a lei 9474/94 sobre a proteção a menores refugiados no Brasil. Concluiu-se que uma legislação adequada é requisito essencial para que um país possa oportunizar e atender mais adequadamente, as crianças refugiadas, normalmente em situação de risco e vulnerabilidade.

Palavras-chave: Crianca refugiada: Vulnerabilidade: Protecão ao menor.
\end{abstract}

\section{Introdução}

Refugiado é todo indivíduo que está fugindo de seu país de origem devido a algum tipo de perseguição que o acomete, seja de alçada racial, religiosa, social, política, dentre outras; em decorrência de grave violação de seus direitos humanos, que tem o causado temores e receito de permanecer ou retornar ao país (MARTUSCELLI, 2014). O conceito existe nas mais diversas culturas e sociedades, sendo um termo familiar para muitos, porém com características e particularidades pouco conhecido pela sociedade, o que tem causado muita confusão e, por vezes, preconceito.

O Brasil possui umas das legislações mais desenvolvidas sobre o tema, além de deter uma ampla rede organizacional e entidades da sociedade civil, responsáveis por auxiliar os refugiados e os solicitantes em todo o território. Segundo dados divulgados pelo Comitê Nacional para Refugiados - CONARE, hodiernamente existem cerca de 4.500 refugiados no Brasil, das mais diversas nacionalidades. Em 2012, o país recebeu cerca de 2.000 novas requisições de refúgio, das quais 148 foram oriundas pessoas menores de dezoito anos, ou seja, de crianças ou adolescente, sendo quatorze dessas desacompanhados (PEREIRA, 2000).

Nesse sentido, sendo patente a presença de menores refugiados, além da Lei 9.474/97, é possível a aplicação do Estatuto da Criança e do Adolescente, que internaliza 
as disposições da Convenção das Nações Unidas sobre os Direitos da Criança de 1989, às crianças refugiadas.

Como atualmente as crianças totalizam quase metade do quantitativo de refugiados ao redor do mundo, resta imperioso que seja conferida uma proteção e observância especial as mesmas, pois são naturalmente indivíduos mais frágeis e vulneráveis, principalmente quando se apresentam como desacompanhadas, que se encontram apartadas de seus pais ou responsáveis, situação que potencializa o quadro de vulnerabilidade.

Tanto em relação aos refugiados adultos, quanto as crianças refugiadas, chegou-se a conclusão que a melhor forma de ajuda-los é facilitando e colaborando para sua inserção na comunidade local. Para tanto, tem se mostrado importante escutar as necessidades pessoais de cada indivíduo, principalmente porque a cultura do refugiado por ser totalmente diversa da praticada no Brasil.

Para que isso seja possível, é importante que não só os adultos, mas os menores sejam escutados quando em relação a uma decisão que venha a afeta-lo de alguma forma, para que seja possível atender seu interesse ou, pelo menos, identificar o melhor interesse a ser defendido ou aplicado para aquele menor, sendo essencial levar em conta todas as particularidades do caso, assim como a forma que a decisão irá afetar em sua vida.

Com base nisso, no presente estudo analisaremos os direitos dos menores refugiados no Brasil, bem como a importância do Princípio do Melhor Interesse da Criança na persecução e defesa efetiva dos direitos dos menores.

\section{Breves considerações acerca do histórico mundial e nacional da Lei 9474/97.}

Em 1997, o Brasil aderiu aos preceitos da Convenção do Estatuto do Refugiado de 1951, que foi um dos primeiros pactos internacionais versando sobre direitos humanos ${ }^{1}$. Com isso, surgiu a Lei 9.474/97, sendo este um verdadeiro marco na trajetória brasileira sobre o direito dos refugiados, cujos pontos principais exigem a observância: (i) da

\footnotetext{
${ }^{1}$ Comente-se que, apenas em 1959, ou seja, mais de dez anos após a Declaração Universal de Direitos Humanos, a Organização Nacional das Nações Unidas - ONU editou a Declaração Universal dos Direitos da Criança.
} 
individualidade do caso concreto; e (ii) do investimento em políticas públicas que visem integrar os refugiados na sociedade ${ }^{2}$.

Assim direito dos refugiados teve início em 1952, com a Convenção sobre o Estatuto do Refugiado, em que o Brasil foi signatário. A seguir, em 1961, por meio do Decreto 50.215, foi promulgado o referido diploma no ordenamento jurídico brasileiro, no entanto, havia uma "reserva geográfica", em que o país apenas aceitava refugiados oriundos do continente europeu.

Em 1972, o Decreto 70.946 promulgou o Protocolo de 1967, relativo ao Estatuto dos Refugiados, que passa a ser norma vigente no país. Já em 1977, o Alto Comissariado das Nações Unidas no Brasil, detentor de limitações, pois apenas podia reassentar os refugiados em um outro país sul-americano, tais como Chile, Argentina, Uruguai e Paraguai. E apenas em 1982 a ACNUR - Alto Comissariado das Nações Unidas para Refugiados (ACNUR, 2011) é oficialmente reconhecida pelo Governo do Brasil e, em 1989, é transferido para Brasília.

Sequencialmente, em meados de 1979-1980, ocorre a situação em que diversos vietnamitas são acolhidos pelo Brasil, porém não são passíveis de receber a classificação de refugiados devido a cláusula da reserva geográfica, sendo-lhes, no entanto, conferido aos vietnamitas um estatuto migratório alternativo. Em 1986, ocorre fato semelhante, em que o Brasil acolhe cinquenta famílias Bahai's, cerca de duzentos iranianos, que são vistos como asilados, em razão da mesma reserva geográfica.

No final de 1989, levanta-se a reserva geográfica, o que possibilitou que, entre 1992 e 1994, o país acolhesse angolanos que foram compelidos a sair do seu país de origem após as últimas eleições, que apesar de não se encaixarem na definição de refugiados, foram recebidos pelo Brasil como tais, com base na aplicação na Declaração de Cartagena ${ }^{3}$.

Em 1996, há a edição do projeto de lei que visa incorporar a Convenção de 1951 (ONU, 1951) ao Direito brasileiro, que dá origem a Lei n. 9.474/97. Depois da promulgação da Lei n. 9.474/97, houve a aprovação de uma resolução que regulamenta a

\footnotetext{
${ }^{2}$ Antes do advento da Lei 9.474/97, isso era realizado pelo Alto Comissariado das Nações Unidas para Refugiados - ACNUR. É a primeira norma brasileira voltada para criar uma estrutura na Administração voltada para os direitos dos refugiados, assim como procedimentos específicos para fins de implementar o referido pacto internacional de Direitos Humanos (ALMEIDA, 2000, p. 374).

${ }^{3}$ Essa Declaração prevê a classificação de refugiado para indivíduos submetidos à "grave e generalizada violação de direitos humanos", que estejam sofrendo perseguição de cunho racial, religioso, social oi político; situação em que os angolanos se encaixavam.
} 
solicitação de refúgio, que confere ao solicitante a autorização de estadia provisória no Brasil até que seu pedido seja julgado, permitindo, ainda, que ele trabalhe nesse período.

Refugiado é, segundo a Convenção de 1951 é:

(...) qualquer pessoa: que, em consequência de acontecimentos ocorridos antes de 01 de janeiro de 1951, e receando com razão ser perseguida em virtude da sua raça, religião, nacionalidade, filiação em certo grupo social ou das suas opiniões políticas, se encontre fora do país de que tem a nacionalidade e não possa ou, em virtude daquele receio, não queira pedir a proteção daquele país; ou que, se não tiver nacionalidade e estiver fora do país no qual tinha a sua residência habitual após aqueles acontecimentos, não possa ou, em virtude do dito receio, a ele não queira voltar (ONU, 1951).

Assim, refugiado é todo indivíduo que sofre algum tipo de perseguição no campo racial, religioso, social político etc.; que venha ameaçar sua vida ou sua liberdade. Essa definição, presente na Convenção de 1951, essa definição surgiu com o escopo de proteger indivíduos submetidos a possíveis situações de limitação de mobilidade provocada pela Segunda Guerra Mundial.

Como naquela época, não se podia imaginar que a problemática dos refugiados se tornaria algo crônico, motivo pelo qual deve se considerar que a Convenção de 1951 está submetida a um limite temporal, em que são reconhecidos como refugiados as pessoas que foram perseguidas antes de $1^{\mathrm{a}}$ de janeiro de 1951 , nos termos do $\operatorname{artigo} 1^{\mathrm{o}}, \mathrm{a}, \S 2^{\mathrm{o}}$ da Convenção, sendo esse limite superado com o Protocolo de 1967.

A concepção na forma ampliada tem origem na Convenção da Organização da Unidade Africana publicada em 1974 (OUA, 1974), que determinou em seu artigo $1^{\circ}$, inciso 2, que:

O termo 'refugiado' aplicar-se-á também a toda pessoa que, por causa de uma agressão exterior, uma ocupação ou uma dominação estrangeira, ou de acontecimentos que perturbem gravemente a ordem pública em uma parte ou na totalidade de seu país de origem, ou do país de sua nacionalidade, está obrigada a abandonar sua residência habitual para buscar refúgio em outro lugar fora do seu país de origem ou do país de sua nacionalidade (OUA, 1974).

Essa forma ampliada do termo relaciona-se com a definição de asilo, que deriva da palavra grega "a-sylum", em que o prefixo "a" tem teor de negação, significando "nãoviolência", logo, aquele que busca por asilo, trata-se de pessoa que está fugindo de alguma situação de violência. Assim, oferecer asilo à uma pessoa, significa protegê-la de alguma 
situação de violência, proporcionando um local seguro para que possa viver e desfrutar de sua liberdade.

No direito internacional, utiliza-se de dois termos para se referir a alguém que busca asilo, sendo eles asylum seeker (buscador de asilo) e refugee (refugiado). Em regra, o primeiro saiu do seu país de residência e está em outro país buscando por proteção, já segundo, consiste em indivíduo que já deu início ao processo de concessão de refúgio, conforme definido no Estatuto de Refugiado do país (ALMEIDA, 2000, p. 378).

Deve-se ressaltar que a definição clássica é numerus clausus, de forma que há um espaço de interpretação dentro das cinco possibilidades de perseguição, não podendo ser adicionadas outras causas; ao contrário do que ocorre com a forma ampliada disposta na Convenção da OUA (1974), cuja definição buscou descrever uma situação coletiva, em que os indivíduos se encontram sob algum tipo de ameaça decorrente dos acontecimentos ocorridos na África desde 1956, abarcando um quantitativo muito maior de possibilidades em que a pessoa pode ser considerada como vulnerável e carente de proteção. A definição ampliada surge na Declaração de Cartagena de 1984 (CARNEIRO apud SILVA, 2012), da seguinte forma:

Reiterar que, em vista da experiência tida em função da afluência massiva de refugiados na área centro-americana, faz-se necessário encarar a extensão do conceito de refugiado, tendo-se em conta, no pertinente, e dentro das características da situação existente na região, o precedente da Convenção da OUA $\left(\operatorname{art.~} 1^{\circ}, \S 2^{\circ}\right)$ e a doutrina utilizada nos informes da Comissão Interamericana de Direitos Humanos. Desse modo, a definição ou conceito de refugiado recomendável para sua utilização na região é aquela que além de conter os elementos da Convenção de 1951 e do Protocolo de 1967, considere também como refugiados as pessoas que fugiram de seus países porque sua vida, segurança ou liberdade foram ameaçadas pela violência generalizada, a agressão estrangeira, os conflitos internos, a violação massiva dos direitos humanos ou outras circunstâncias que tenham perturbado gravemente a ordem pública.

O Brasil, por sua vez, apesar de não ser signatário da supracitada declaração, aplica a forma ampliada desde 1989, ano em que foi levantada a "reserva geográfica". Em razão disso, a Lei 9.474/97 (BRASIL, 1997), trouxe a definição, em seu artigo 1a, III, de que refugiado é todo indivíduo que esteja sofrendo alguma forma grave e generalizada de desrespeito de seus direitos humanos, que foi compelido a deixar o país e está em busca de refúgio em outro. 
A legislação brasileira voltada para proteção dos refugiados, é considerada uma das normas mais avançadas e generosas existentes na América, o que faz com que diversos seres humanos, dos mais diversos países, já tenham buscado e encontrado refúgio no Brasil, o que transforma o país em um verdadeiro aliado e espaço de distinção humanitária na América, devendo-se ressaltar que os refugiados permanecem no Brasil não por que querem, mas por que precisam (ALMEIDA, 2000, p. 380).

\section{Da legislação protecionista das crianças refugiadas no Brasil}

Inicialmente, cabe trazer à baila o conceito de criança refugiada. Partindo da definição internacionalmente aceita e presente na Convenção dos Direitos da Criança (UNICEF, 1989), que define, em seu artigo $1^{\circ}$, criança como todo indivíduo com menos de dezoito anos, salvo se emancipado nos termos da legislação local.

A Convenção dos Direitos da Criança trata-se de documento relativo aos direitos humanos das crianças que detém a maior aceitação universal da história, pois apenas a Somália e os Estados Unidos da América não a ratificaram, mas assinaram o documento formalmente. Esta Convenção foi adotada em 1989 pela Assembleia Geral das Nações Unidas e oficializada como Convenção internacional em 1990. O documento conferiu força legal as disposições já constantes na Declaração Universal dos Direitos das Crianças, e foi a responsável por, pela primeira vez, os menores serem vistos como titulares de direitos fundamentais.

Ao ratificarem o referido documento, os Estados se comprometeram a respeitar os direitos civis, socioeconômicos, culturais e políticos dos menores; tal como ocorre com os adultos, protegendo-os de situações de fome, pobreza, violência, dentre outras injustiças e dificuldades, devendo, ainda unir esforços no sentido de desenvolver as capacidades das crianças. $\mathrm{O}$ documento prevê medidas inovadoras, mormente em relação às situações de guerra e outras em que o menor esteja em conflito com a legislação, aos casos de exploração de crianças e adolescentes e, ainda, referente à casos em que a criança seja participante de grupo minoritário.

A Convenção Internacional é regida pelos seguintes princípios: (i) da não discriminação, com base no qual os Estados devem assegurar o direito de todos, independente de raça, gênero, religião ou outra forma de discriminação; (ii) do melhor 
interesse da criança, relacionado aos interesses dos menores, que deve ocupar uma posição prioritária em todo e qualquer tipo de ação que o envolva; (iii) do direito à vida, que motiva os Estados (iv) do direito à participação, referente ao direito de participar e de manifestar sua opinião nas decisões que lhe toquem, devendo sempre ser levado em conta o grau de maturidade da criança (SANTOS, 2012, p.16).

Segundo afirma Ana Carolina C. dos Santos (2012), em sua dissertação de mestrado sobre crianças refugiadas, na Convenção de 1951 - documento que define o conceito do que é refugiado-, nota-se que inexiste definição para o que é criança refugiada, bem como não há menções especiais sobre a aplicação de outra norma aos menores, sendo possível inferir que a citada Convenção também se aplica aos menores refugiados, principalmente na parte que se refere ao indivíduo pertencer à algum grupo social, que abarca, não só criança, mas também mulheres, vítimas tráfico, de exploração etc.

Deve-se ressaltar que, apesar da Convenção de 1951 não trazer qualquer disposição acerca da definição do que seria uma criança refugiada, este diploma garante o direito a educação para toda as crianças sem qualquer discriminação, conforme pode se verificar em seu artigo 22. Ademais, assim como ocorre na Convenção de 1951, a lei brasileira 9.474/1997 não traz qualquer disposição acerca da definição do que seria uma criança refugiada.

A autora complementa que, pelo mesmo motivo, deve-se entender que a definição envolve também os menores refugiados desacompanhados, que são crianças que foram separadas de seus pais ou familiares e que, em razão disso, estão sem atenção e cuidado de nenhum outro adulto que se apresente como responsável pelo menor. Deve-se comentar que segundo o ACNUR, os menores refugiados desacompanhados são crianças com menos de dezoito anos que estejam fora de seu antigo país de residência e separadas de seus pais ou responsáveis (SANTOS, 2012, p.17).

É incontroverso que crianças desacompanhadas correm potencial risco de não receberem a proteção adequada e/ou o cuidado adequado, isto porque os pais ou outros responsáveis do menor, são fonte principal no sentido de garantir a integridade psíquica e física do menor, razão pela qual a separação da crianças dessas pessoas, pode vir a ocasionar danos psicológicos. Muitas delas são cuidadas por outros refugiados, mas isso não é garantia de que as suas necessidades serão asseguradas, já que estes também se encontram em situação de fragilidade. Assim, as crianças desacompanhadas são 
potencialmente mais vulneráveis e correm mais risco de serem negligenciadas, violentadas, abusadas, dentre outras situações de perigo.

Os programas que visam ajudar os refugiados devem ter, como principal alvo, prestar assistência aos refugiados, principalmente quando estiverem em composição de famílias, para fins de evitar e prevenir a separação desses membros. Assim, é essencial que se identifiquem os componentes de uma família, assim como as crianças que estejam desacompanhadas, o mais breve possível, para que todos tenham o acompanhamento necessário e peculiar a depender da situação que se encontre, sendo importante garantir a união da família ou a busca pelos parentes ou responsáveis, no caso dos menores sem acompanhantes.

Conforme foi mencionado, o Brasil é signatário de tratados internacionais que versam sobre refugiados, dos quais surgiu a Lei 9.474/07; bem como dispõe de legislações específicas relativas a proteção de indivíduos que podem ser aplicadas em casos específicos de refugiados, como é o caso do Estatuto da Criança e Adolescentes - ECA, Lei 8.069/90 (BRASIL, 1990), que pode ser aplicado para fins de salvaguardar direitos e proteger menores em situação de refúgio.

A lei brasileira 9.474/97, baseada na Convenção de 1951, reconhece como refugiado todo e qualquer indivíduo que esteja fugindo de seu país devido a perseguição em razão de sua raça, opção religiosa, nacionalidade, entendimentos políticos, do grupo social que faz parte, ou, ainda, por estar submetido a situação de violação dos seus direitos humanos. O referido diploma legal também foi responsável pela criação do CONARE, órgão detentor de estrutura tripartite composto por representantes do Governo, da sociedade civil e da ACNUR, que é responsável por decidir acerca dos casos dos solicitantes de refúgio, reconhecendo-os ou não na condição de refugiados, e, ainda, por estabelecer políticas públicas para esse grupo de indivíduos.

Essa legislação abarca princípios importantes para os refugiados, tais como: (i) a não discriminação entre os nacionais, os solicitantes de refúgio e os refugiados; e (ii) o non-refoulement, que diz respeito a vedação da devolução do refugiado para o país de origem dos solicitantes que estejam com sua liberdade e sua vida ameaçadas. O Brasil também dispões de um Programa de Reassentamento Solidário voltado para receber indivíduos refugiados que precisam ser alocados em um terceiro país com a finalidade de obter asilo, tal como Colômbia ou Equador. 
Outrossim, a Lei 9.474/97, inova ao conceder o direito à reunião familiar, que oportuniza que a condição de refugiado seja estendida para todos os membros da família que estejam no Brasil, sendo passo importante principalmente em relação aos menores refugiados que estão separados de seus pais. No entanto, apesar de ser algo legalmente previsto, o país não dispõe de mecanismos formais efetivos que permitam realizar essa reunião da família e extensão da condição de refugiado para todos (SANTOS, 2012).

Por seu turno, o ECA consiste em norma brasileira responsável por garantir os direitos das crianças e adolescentes. Diferente do que está disposto na Convenção dos Direitos da Criança e no entendimento na ACNUR, para o ECA, as crianças são indivíduos até doze anos de idade, e os adolescentes são jovens que possuam de doze a dezoito anos de idade, entendendo que este conceito se aplica inclusive aos menores oriundos migração forçada.

O referido Estatuto foi elaborado tomando como base que as crianças e adolescentes, assim como os indivíduos adultos, são sujeitos de direitos, bem como com base em princípios favoráveis à proteção dos menores, dos quais destacamos o Princípios do Superior Interesse da Criança. O documento visa possibilitar a proteção prioritária e integral dos menores, bem como na responsabilização de forma principal e solidária do Poder Público quanto a proteção desse grupo de indivíduos.

Nesse diapasão, originou-se uma legislação que não admite que nenhum menor sofra algum tipo de negligência, ato discriminatório, violência, crueldade ou qualquer forma de opressão. Além disso, impõe o direito dos menores aos serviços de saúde; à liberdade de ir e vir, de opinião e de expressão, de crença e religião; à participação na vida familiar e na vida comunitária sem qualquer tipo de discriminação, a participar da vida política, bem como o direito de solicitar e obter o asilo.

O direito a educação também consiste em previsão legal existente no ECA, que determina que o Estado Brasileiro tem o dever de oferecer um ensino público de qualidade, desde a creche até o ensino médio, para todos os menores; afirma, ainda, que durante o processo de ensino os valores referentes a cultura, artes e história das crianças devem ser respeitados, como forma de promover a liberdade de criação e de acesso aos recursos culturais e históricos. Indubitavelmente esta última disposição em relação a forma de ensino é de grande valia para os menores refugiados, uma vez que esses são oriundos de outras culturas, que, inclusive, podem ser muito diferentes da que é praticada no Brasil. 
Com base no exposto, nota-se que a proteção brasileira quanto as crianças refugiadas tem como base a Lei 9.474/97, que dispões sobre os refugiados, e no Estatuto da Criança e do Adolescente, que é voltado especialmente para menores e que, sem dúvidas, deve ser aplicado as crianças refugiadas residentes em solo brasileiro. Sendo assim, os menores refugiados possuem os mesmos direitos e proteção no sistema jurídico brasileiro, que as crianças e adolescentes brasileiros detém.

Infelizmente, na prática alguns direitos são negligenciados, tal como é o direito à participação, o que prejudica diretamente a observância de outras necessidades durante o processo de integração no país, ocasionando diversas barreiras durante esse período. $\mathrm{O}$ primeiro grande entrave diz respeito ao idioma do Brasil; e o segundo, é a discriminação. Mesmo com a evolução da sociedade e da disseminação da importância do respeito dos direitos humanos, muitas crianças ainda são vítimas de discriminação nas escolas ou em outros locais, tal como hospitais ${ }^{4}$, isto porque a maioria da população desconhece os pormenores do instituto do refúgio, o que faz com que, por vezes, confundam os refugiados com fugitivos (SANTOS, 2012).

Sendo assim, é valioso que seja oportunizado que as crianças refugiadas se expressem, para que estas possuam um espaço efetivamente participativo em sua inserção social e no seu desenvolvimento como um todo, isto porque esse grupo social também são atores sociais que precisam ser escutados, mormente por possuírem visões e necessidades próprias, como forma de garantir a proteção integral e efetiva desses menores.

Contudo, no cenário brasileiro, o que se presencia é um quadro onde nem refugiados adultos, tampouco crianças refugiadas, detém de mecanismos formais de participação, de forma que os menores refugiados ocupam uma posição de indivíduos duplamente excluídos dos espaços políticos e das tomadas de decisões. Segundo Ana Carolina Carvalho dos Santos (2012), isso ocorre mormente em razão da sociedade, em regra, enxergar as crianças como seres imaturos e incapazes de participar ativamente dos espaços políticos, de forma que são impedidas, inclusive, de opinar sobre diversos assuntos que possam impactar diretamente suas vidas.

Assim, a proteção que o Brasil dispõe para crianças refugiadas, apesar de buscar garantir juridicamente todos os direitos do menor, não dispõe de espaço de participação

\footnotetext{
${ }^{4}$ Em relação a dificuldade de acesso à educação e à saúde, estas dizem respeito ao idioma, que é dominado pela população nativa do Brasil, bem como as burocracias, que são mais conhecidas pelos habitantes nacionais do país. Já os refugiados, além de não dominarem o idioma, não possuem, em regra, os documentos exigidos pela burocracia do país (SANTOS, 2012)
} 
para que a criança se expresse, o que impossibilita que esta tenha todas suas necessidades atendidas no processo de integração no país local.

\section{O melhor interesse para a criança e o direito brasileiro}

Com base nessas legislações e nos princípios já apresentados, a partir da análise das decisões proferidas pelo CONARE, é possível se verificar que este tem se posicionado mormente com base no Princípio do Interesse Superior da Criança, o que revela a importância deste no processo de integração da criança refugiada no país.

Para Heloisa Helena Barboza (2000, p. 203), a Convenção Internacional sobre os Direitos da Criança e do Adolescente foi responsável por consagrar, especialmente no âmbito internacional, os direitos próprios dos menores, possibilitando que esses passem a ser vistos como membro da sociedade, assim como os adultos. Gustavo F. de Campos Monaco (2009, p.445-446), complementa ao afirmar que o referido diploma representa a mudança da normatização anterior, que considerava a criança como um ser passivo e objeto de proteção, e agora passa a ocupar a posição de sujeito de direitos, momento em que a observância do Princípio do Melhor Interesse do Menor se faz necessária ${ }^{5}$.

Especificamente em relação ao ordenamento brasileiro, a inserção de princípios na Constituição de 1988, chamada de constituição cidadã, tal como o Princípio da Dignidade, que marca a passagem do regime político militar para o democrático, (LAFER, 2005, p. 13), em que, além da ampliação dos direitos fundamentais dos homens, criou um arcabouço legislativo especialmente relativo aos menores de dezoito anos, conferindo-lhes direito à dignidade, liberdade, bem como à autonomia, que se tornam exigível desde então.

A mesma mudança pode ser verificada no ECA, que em seu artigo 15 afirma que os menores são sujeitos de direitos e seu artigo $3^{\circ}$ determina que todo menor tem direito a todos os direitos fundamentais constitucionalmente postos, que devem ser respeitados para fins de oportunizar que as crianças e adolescentes possam se desenvolver com a devida liberdade e dignidade.

Nesse contexto, o interesse da criança se apresenta como fundamental para melhor atender as necessidades do menor. Sua importância é tamanha que, apesar do Princípio do

\footnotetext{
${ }^{5}$ Urge comentar que o mesmo ocorreu no ordenamento interno do Brasil, que, com a consagração do direito fundamental da dignidade da pessoa humana na Constituição de 1988, estendeu aos menores a imposição de respeito e proteção de sua dignidade (MARTUSCELLI, 2014).
} 
Melhor Interesse da Criança não constar de forma expressa na Constituição de 1988 ou no ECA, a doutrina tem se posicionado no sentido deste ser inerente à proteção integral, disposta no artigo 227, caput da Constituição, bem como no primeiro artigo do Estatuto (FACHIN, 2003, p. 584). Ainda, é apontado como critério hermenêutico e cláusula geral dos direitos constitucionais fundamentais dos menores (BARBOZA, 2000, p. 206).

Alguns autores entendem que este princípio também é desdobramento do artigo $6^{\circ}$ do ECA, que determina que "na interpretação desta Lei levar-se-ão em conta os fins sociais a que ela se dirige, as exigências do bem comum, os direitos e deveres individuais $e$ coletivos, e a condição peculiar da criança e do adolescente como pessoas em desenvolvimento", onde fica claro a relevância da situação particular das crianças e adolescentes, que deve ser considerava inclusive na atividade interpretativa ${ }^{6}$. Outrossim, é possível verificar a existência, de forma explícita, do Princípio do Melhor Interesse do Menor Criança no ordenamento jurídico do Brasil desde a promulgação da Convenção sobre os Direitos da Criança, por meio do Decreto $n^{\circ}$ 99.710/90, que em seu artigo 3.1, determina que todas as ações que envolvam menores devem considerar, primeiramente, $o$ interesse desses indivíduos.

O conceito do referido Princípio assume diversas interpretações ao redor do mundo, algumas com teor quantitativo, que se refere ao "maior interesse", e outro qualitativo, que assume a feição do "melhor interesse" (PEREIRA, 2008. p. 46). No Brasil, como o Princípio está expresso na Convenção e no Decreto como sendo relativo ao melhor interesse, conclui-se que este assume um critério qualitativo no positivo brasileiro e cuja aplicação é obrigatória por força da Constituição, tendo em vista que é originário de norma internacional e incorporado ao ordenamento jurídico com status de lei federal.

Ademais, urge ressaltar que a Lei 12.010/09, que alterou o ECA, acrescentou aos princípios norteadores da aplicação das medidas protetivas o "interesse superior da criança e do adolescente", o que torna explícito o Princípio do Melhor Interesse da Criança na referida Lei.

Conforme comentado, a Convenção dos Direitos da Criança define criança com sendo todo indivíduo com menos de dezoito anos, e acrescenta que devem ser tratados sem qualquer tipo de discriminação. Seguindo o disposto na Convenção, o ECA estabeleceu a

\footnotetext{
${ }^{6}$ Conforme ensina Noberto Bobbio (1995. p. 219-220), isso é chamado de analogia iuris, por meio da qual sendo patente as diversas possibilidades de indução das normas, é possível se utilizar essa forma de interpretação integrativa para fins de salvaguardar os interesses dos envolvidos.
} 
proteção integral de todos os direitos de toda criança e adolescente, independente de sua situação familiar.

Nesse meio, o Princípio do Melhor Interesse, exige uma maior atenção as necessidades do menor, possuindo início dentro do ambiente familiar, em que deve-se tratar a criança como sujeito de direito, o que também repercute no poder familiar, cujo foco de interesses mudará dos agentes de poder para os destinatários, sendo estes os menores (SCAFF, 2010. p. 575). Assim, o poder de família passar a ser um tipo de intervenção dos pais na esfera jurídica dos menores, mas não em seus interesses (TEPEDINO, 2008. p. 881).

Nesse diapasão, a doutrina se posiciona no sentido de que o poder familiar está limitado em benefício da criança, assumindo natureza de "poder vinculado para a realização de um fim específico (SCAFF, 2010. p. 575), que deve ser aplicado para fins de alcançar o melhor interesse dos filhos, com objetivo de torná-lo ser independente no futuro (TEPEDINO, 2008. p. 882). Nota-se, então, que a aplicabilidade do Princípio do Melhor Interesse impõe limites ao exercício do poderio familiar, de forma que este perdeu o papel de instituto essencial no Direito de Família, que foi substituído pelos princípios e disposições existentes no ECA e na Constituição de 1988 (FACHIN, 1996, p. 83).

Apesar da importância desse Princípio ${ }^{7}$, ele encontra algumas dificuldades de ser efetivamente aplicado. No Brasil, por exemplo, a Constituição de 1988 definiu os menores como sujeitos de direitos, e, ainda estipulou o interesse superior da criança e do adolescente, contudo, no campo jurídico, a aplicação do Princípio depende da interpretação deste em confronto com as demais normas civis (BARBOZA, 2000. p. 211), e, em regra, é tratado como princípio especial, que possui aplicação subsidiária em relação aos princípios gerais do direito (PEREIRA, 2000. p. 224).

De fato, o Princípio é largamente utilizado nos tribunais brasileiros, sendo muito utilizado em processos de adoção, com a finalidade de preservar os vínculos afetivos da criança quanto a família natural. Também é utilizado para negar um pedido de guarda e adoção realizado por uma família não inscrita, como forma de exigir o respeito a ordem do cadastro. Em qualquer caso, o argumento principal se pauta na melhor forma de proteção do interesse do menor.

\footnotetext{
${ }^{7}$ A importância é tamanha que o Comitê para os Direitos da Criança, órgão que monitora o respeito aos direitos dispostos na Convenção, entende que o interesse superior da criança se trata de um dos princípios-base da Convenção, que deve ser observado por todos os poderes de forma sistemática, mormente quando da elaboração das políticas públicas e de saúde (PIOVESAN, 2008, p. 308).
} 
A aplicação do Princípio pode resultar nas mais variadas situações variedade das situações e pode resultar nos mais diversos resultados, em razão de sua abstração, que o torna adaptável aos casos concretos. Deve-se comentar que o melhor interesse a ser escolhido nem sempre está disposto norma concreta, cabendo ao intérprete verificar no caso concreto qual o melhor interesse para o menor. Nesse cenário, a aplicação do Princípio implica encontra diversas barreiras em decorrência de sua ideia vaga, de forma que é possível ocorrer situações em que, em nome do Princípio, seja negada ao menor a proteção integral, isto porque a falta de clareza da definição do instituto, em conjunto com o amplo poder decisório, pode dar ensejo a situações de injustiça (PEREIRA, 2000, p.222).

No entanto, essa abstração e possibilidade adaptativa não possibilita o uso do princípio para meros fins de legitimar decisões que, no final de tudo, não tutela o melhor interesse para a criança. Outrossim, sobre esse aspecto, urge comentar que em muitas situações os pais projetam em seus filhos seus sentimentos e suas características, o que pode causar uma confusão psicológica no menor, que apresentará dificuldade de perceber, bem como de expor, suas reais necessidades (GROENINGA, 2001, p. 78).

Nesse contexto, o uso do Princípio exige a reflexão e observância de outros valores presentes no ordenamento jurídico, que devem ser analisados sem a pretensão de aplica-los de forma rígida e absoluto, mas sim, como forma de contribuir para a proteção do melhor interesse para o menor, que indubitavelmente depende do caso concreto em análise, buscando garantir uma coerência entre os fatos, os valores e os interesses envolvidos no caso em questão; sendo o objetivo final o de assegurar os direitos dos menores.

Sendo assim, e como já comentado, o ECA também deve ser aplicado as crianças refugiadas, o que automaticamente implica no respeito e tutela do melhor interesses para esses menores. Assim, resta imperioso que seja dado voz, escutadas, atendidas e protegidas as necessidades particulares de cada criança, em respeito ao Princípio aqui discutido.

\section{Considerações Finais}

O refúgio é o ato de conceder abrigo e proteção a certo indivíduo que esteja fugindo de seu país de residência por estar sofrendo algum tipo de perseguição arbitrária de cunho racial, religioso, cultural dentre outros. Esses indivíduos podem ser de qualquer gênero ou idade, havendo, inclusive crianças refugiadas. Esses indivíduos são protegidos por diversos direitos, dentre os quais estão aqueles relativos a dignidade da pessoa humana, que visam 
salvaguardar que todo indivíduo tenha seus direitos e cujo principal objetivo é assegurar o bem-estar dos indivíduos.

Hoje em dia, estudiosos entendem que a principal solução para melhor as condições de vida dos solicitantes e refugiados de fato, diz respeito a integração desses indivíduos ao local, que envolve não só as caraterísticas do país de refúgio no qual será inserido, como também as particularidades dos refugiados, momento em que resta imperioso o respeito e observâncias as reais necessidades de cada indivíduo em particular.

Para que isso seja possível, é preciso que o Estado destine esforços no sentido de tutelar os direitos desses indivíduos, assim como que o país desenvolva políticas públicas no sentido de divulgar conteúdo sobre esse tipo de situação, pois boa parte das pessoas não sabem o que é refugiado e as particularidades que estes carregam; assim como elaborar campanhas colaborativas que, por exemplo, expliquem e incentivem a população para que esta colabore com a integração desse indivíduo ao país.

Como comentado, a legislação específica sobre o tema define o termo refugiado, no entanto não dispõe de conceito especial para criança refugiada, motivo pelo qual, por analogia, se considera que seja um menor que esteja fugindo do seu país de origem devido a algum tipo de perseguição.

Dentre essas crianças refugiadas, existem os menores desacompanhados, que são crianças ou adolescentes que foram separados de sua família ou responsáveis por algum motivo. Quanto a este grupo em especial, acreditamos que a principal preocupação deve versar sobre evitar que as crianças sejam separadas de seus familiares, ou, ainda o desenvolvimento de programas sociais voltados para reunir esses menores as suas famílias, sendo, dessa forma, essencial que as crianças desacompanhas sejam identificadas o mais breve possível, seja para tentar reuni-las aos seus pais ou responsável, seja para conferir o tratamento e apoio adequado a esse grupo de refugiados.

Ainda, parece ser importante que o Estado vise elaborar políticas que visem garantir ao máximo a proteção desses menores, que são naturalmente indivíduos acometidos por fragilidade. E, na busca dessa proteção, o respeito e observância as necessidades e interesses desses menores é de suma importância, como forma de evitar injustiças, bem como facilitar sua inserção no país de refúgio.

Hodiernamente, as crianças são vistas como sujeito de direitos, dotados de direitos, liberdades e autonomia, que devem ser respeitados. Para tanto, a Constituição elencou diversos dispositivos legais e princípios, tal como Princípio do Melhor Interesse do Menor, 
que está positivado no artigo 3.1 da Convenção Internacional dos Direitos da Criança, no artigo 227 da Constituição de 1988 e no artigo 100, parágrafo único, IV do Estatuto da Criança e do Adolescente, sendo incontroverso a exigibilidade quanto à sua observância.

O melhor interesse do menor é dotado de muita abstração e generalidade, motivo pelo qual é preciso que outros valores e direitos sejam analisados em conjunto com o caso concreto para fins de aplicar a interpretação coerente e lógica. Nesse cenário, é indubitável que escutar o menor trata-se de requisito essencial no sentido de buscar o seu melhor interesse.

Sobre isso, vale lembrar que o próprio Estatuto da Criança e do Adolescente garante o direito de liberdade e autonomia dos menores, que se podem ser representados pelo direito de ser ouvido, bem como de participar das decisões que lhes dizem respeito de alguma forma. Nesse sentido, é notório que o legislador teve a intenção de valorizar a observância da manifestação de vontade do menor, considerando este um elemento de convicção e influência na interpretação do melhor interesse para este.

Deve-se salientar que a incapacidade civil não constitui um óbice ao direito de participação do menor nas decisões que o envolvam, inclusive, significa uma colaboração útil e eficaz a interpretação das normas, principalmente porque ouvir os interesses do menor não implica a obrigatoriedade de atendimento destes, pois, como já comentado, existe casos em que o menor não é capaz de explicitar suas reais vontade, seja por influência dos pais, seja em decorrência de sua baixa capacidade cognitiva, momento em que os demais atores atuam com a hermenêutica, buscando a harmonia e coerência entre fatos, valores e direitos envolvidos no caso.

Conforme pode-se inferir do estudo, apesar da importância do Princípio do Melhor Interesse, os mais variados problemas que interferem na sua aplicação, sendo estes principalmente decorrente da abstração do conceito e da dificuldade de se saber qual o real interesse da criança ou adolescente. Isso cria uma alerta como forma de evitar que isso enseje uma injustiça ou um desrespeito ao interesse do menor, o que deve envolver um esforço no sentido de observar a experiência jurídica em conjunto com a interpretação das normas, devendo em ambos os casos serem observados os fatos de forma externa, representado pelo ordenamento jurídico, bem como interna ao caso, que abarca os interesses do menor, como forma de realizar um juízo de ponderação adequado dos fatos e valores envolvidos. 
Diante do exposto, sabendo que a participação do menor nos processos que o envolvam se apresenta como requisito essencial e obrigatório, em especial para fins de garantir seus direitos e sua dignidade, deve estimular que a proteção das crianças refugiadas seja acompanhada com a atenção ao que a criança de fato necessita, principalmente porque esta sabe dizer exatamente quais são suas demandas, que podem ser diferentes daquelas entendidas por um político ou acadêmico da área.

Nisso, o Princípio do Melhor Interesse do Menor consiste em ferramenta útil na persecução dos interesses dos menores, e, consequentemente, da tutela de seus direitos e no respeito da condição desses como seres ainda desenvolvimento. Dessa forma, resta patente que isto consiste em requisito essencial para que um país possa oportunizar que as crianças sejam devidamente integradas ao local, seja inserida em sua família natural, ou em uma substituta, o que, de qualquer forma, exige o respeito a todos seus direitos e interesses.

\section{Referências}

ACNUR - Alto Comissariado das Nações Unidas para Refugiados. Manual de procedimentos e critérios para a determinação da condição de refugiado: de acordo com a Convenção de 1951 e o Protocolo de 1967 relativos ao Estatuto dos Refugiados. 3. ed. 2011. Disponível em: <http://www.acnur.org/t3/fileadmin/Documentos/portugues/ Publicacoes/2013/Manual_de_procedimentos_e_criterios_para_a_determinacao_da_condic ao_de_refugiado.pdf?view=1>. Acesso em: 08 mar. 2019.

ALMEIDA, Guilherme Assis de. A lei n. 9.474/97 e a definição ampliada de refugiado: breves considerações. Revista Da Faculdade De Direito, Universidade De São Paulo, 95, p. 373-383, 2000.

BARBOZA, Heloisa Helena. O princípio do melhor interesse da criança e do adolescente. In: A família na travessia do milênio. Anais do II Congresso Brasileiro de Direito de Família. Coord. Rodrigo da Cunha Pereira. Belo Horizonte: IBDFAM: OAB-MG: Del Rey, 2000.

BOBBIO, Norberto. O positivismo jurídico. Lições de filosofia do direito. São Paulo: Ícone, 1995.

BRASIL. Lei n. 9.474 de 22 de julho de 1997. In ACNUR; IMDH. Lei 9.474/97 e Coletânea de Instrumentos de Proteção Internacional dos Refugiados. Brasília, 2010.

. Leis e decretos. Lei n.8069, de 13 de julho de 1990: dispõe sobre o Estatuto da Criança e do Adolescente e dá outras providências. Brasília, 1990. 
CARNEIRO, Wellington P. A Declaração de Cartagena de 1984 e os Desafios da Proteção Internacional dos Refugiados, 20 Anos Depois. In SILVA, César Augusto (org.). Direitos Humanos e Refugiados. Dourados (MS): Editora UFGD, 2012.

FACHIN, Luiz Edson. O princípio do melhor interesse da criança e a suspensão da extradição de genitora de nacionalidade estrangeira. In: Questões de Direito Civil contemporâneo. Rio de Janeiro: Renovar, 2008.

FACHIN, Luiz Edson. Da paternidade, relação biológica e afetiva. Belo Horizonte: Del Rey, 1996.

FONSECA, Aurora. A Convenção dos Direitos da Criança e a legislação portuguesa, Lisboa: Civitas, 1999.

GROENINGA, Giselle. Do interesse à criança ao melhor interesse da criança contribuições da mediação interdisciplinar. Revista do Advogado, n. 62, março, 2001.

GONÇALVES, Camila de Jesus Mello. Breves considerações sobre o princípio do melhor interesse da criança e do adolescente. Revista Brasileira de Filosofia, v. 236, p. 161-182, 2011.

LAFER, Celso. A internacionalização dos direitos humanos. Barueri: Manole, 2005.

LEITE, Larissa. O devido processo legal para o refúgio no Brasil. Tese (Doutorado em Direito). Universidade de São Paulo, Faculdade de Direito, São Paulo, 2014.

MARTUSCELLI, Patrícia Nabuco. A Proteção Brasileira para crianças refugiadas e suas consequências. Revista Interdisciplinar de Mobilidade Humana, v.22, n.42, Brasília, Jan/Jun, 2014.

MONACO, Gustavo Ferraz de Campos. O Direito Internacional dos Direitos Humanos da Criança e do Adolescente e a Jurisprudência do Supremo Tribunal Federal. In: AMARAL Jr., Alberto do. JUBILUT, Liliana Lyra (orgs.). O STF e o Direito Internacional dos Direitos Humanos. São Paulo: Quartier Latin, 2009.

ONU. ALTO COMISSÁRIO DAS NAÇÕES UNIDAS PARA OS REFUGIADOS. Convenção relativa ao estatuto dos refugiados de 1951. Disponível em: https://www.acnur.org/fileadmin/Documentos/portugues/BDL/Convencao_relativa_ao_Est atuto_dos_Refugiados.pdf>. Acesso em: 22/05/2019.

OUA. ORGANIZAÇÃO DE UNIDADE AFRICANA. Convenção da organização de unidade africana (OUA) que rege os aspectos específicos dos problemas dos refugiados em África. 1974. Disponível em: http://www.refugiados.net/cid_virtual_bkup/asilo2/2couaapr.html>. Acesso em: $22 / 05 / 2019$.

PEREIRA, Tânia da Silva. Direito da criança e do adolescente. Uma proposta interdisciplinar. 2. ed. Rio de Janeiro: Renovar, 2008. 
PEREIRA, Tânia da Silva. O princípio do melhor interesse da criança: da teoria à prática. In: A família na travessia do milênio. Anais do II Congresso Brasileiro de Direito de Família. Coord. Rodrigo da Cunha Pereira. Belo Horizonte: IBDFAM: OAB-MG: Del Rey, 2000.

PIOVESAN, Flávia Piovesan (Coord.). Código de direito internacional dos direitos humanos anotado. São Paulo: DPJ editora, 2008.

RODRIGUES, Noronha. A história do Direito de Asilo no Direito Internacional, Âmbito Jurídico.com.br, 2008. Disponível em: < http://www.ambitojuridico.com.br/site/?n_link=revista_artigos_leitura\&artigo_id=4561\&revista_caderno $=16$ >. Acesso em: 22/05/2019.

SANTOS, Ana Carolina Carvalho dos. Crianças refugiadas: O Princípio do melhor interesse da criança. Dissertação (Mestrado em Direito Penal), Universidade Católica Portuguesa Centro Regional do Porto Escola de Direito, Porto, 2012.

SCAFF, Fernando Campos. Considerações sobre o poder familiar. In: Direito de Família no novo milênio. Estudos em homenagem ao professor Álvaro Villaça Azevedo. José Fernando Simão, Jorge Shiguemitsu Fujita, Silmara Juny de Abreu Chinellato, Maria Cristina Zucchi, org. São Paulo: Atlas, 2010.

TEPEDINO, Gustavo. A Tutela Constitucional da Criança e do Adolescente: Projeções Civis e Estatutárias. In: SARMENTO, Daniel. IKAWA, Daniela. PIOVESAN, Flávia (Coords.). Igualdade, diferença e direitos humanos. Rio de Janeiro: Lumen Juris, 2008.

UNICEF BRASIL. A Convenção sobre os Direitos da Criança. Disponível em: < https://www.unicef.org/brazil/convencao-sobre-os-direitos-da-crianca>. Acesso em: 22/05/2019.

UNICEF. Convenção sobre os direitos da criança. Nova Iorque: UNICEF, 1989. Disponível em <http://www.unicef.org/brazil/pt/resources_10120.htm>. Acesso em 15 de março de 2019.

\section{How to cite this article (APA format):}

Campelo, Maria Paula Silvestre; Carvalho, Maria das Graças; Alencar, Maria Patrícia de; Farias, Athena de Albuquerque; Vidal, Eglidia Carla Figueiredo; Esmeraldo, Carmem Ulisses Peixoto (2019). A Lei 9474/97 e a Proteção a Menores Refugiados. Am. In. Mult. J., October. (7) 4, 59-78.

Received: 09/12/2019;

Accepted: 10/10/2019. 